Supporting Information

for

\title{
Fabrication of a Photocatalyst with Biomass Waste for $\mathrm{H}_{2} \mathrm{O}_{2}$ Synthesis
}

Liangpang $\mathrm{Xu},{ }^{\dagger}$ Yang Liu,${ }^{\dagger}$ Lejing Li, ${ }^{\dagger}$ Zhuofeng Hu,,${ }^{*}{ }^{*}$ and Jimmy C. Yu ${ }^{\dagger, *}$

†Department of Chemistry, The Chinese University of Hong Kong, Shatin, New Territories, Hong Kong, 999077, China

\School of Environmental Science and Engineering, Guangdong Provincial Key Laboratory of Environmental Pollution Control and Remediation Technology, Sun Yat-sen University, Guangzhou, 510275, China

*Corresponding authors Zhuofeng Hu, email: huzhf8@mail.sysu.edu.cn; Jimmy C. Yu, email: jimyu@cuhk.edu.hk

Submitted to ACS Catalysis

The supporting information contains 13 figures, 2 tables, and 8 pages. 


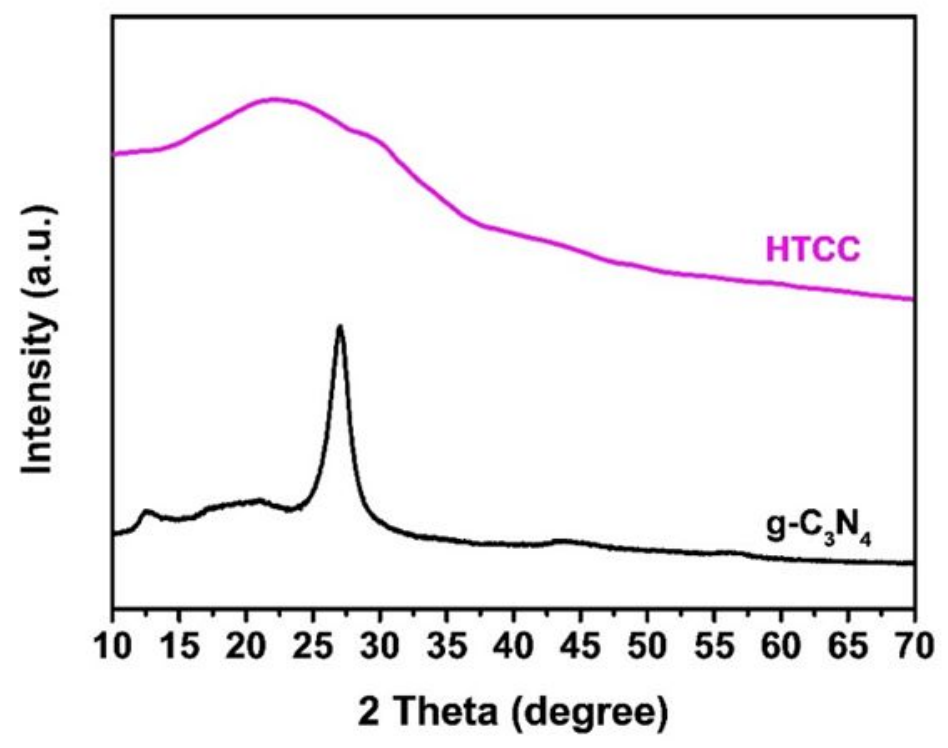

Figure S1. XRD patterns of HTCC and $g-\mathrm{C}_{3} \mathrm{~N}_{4}$.

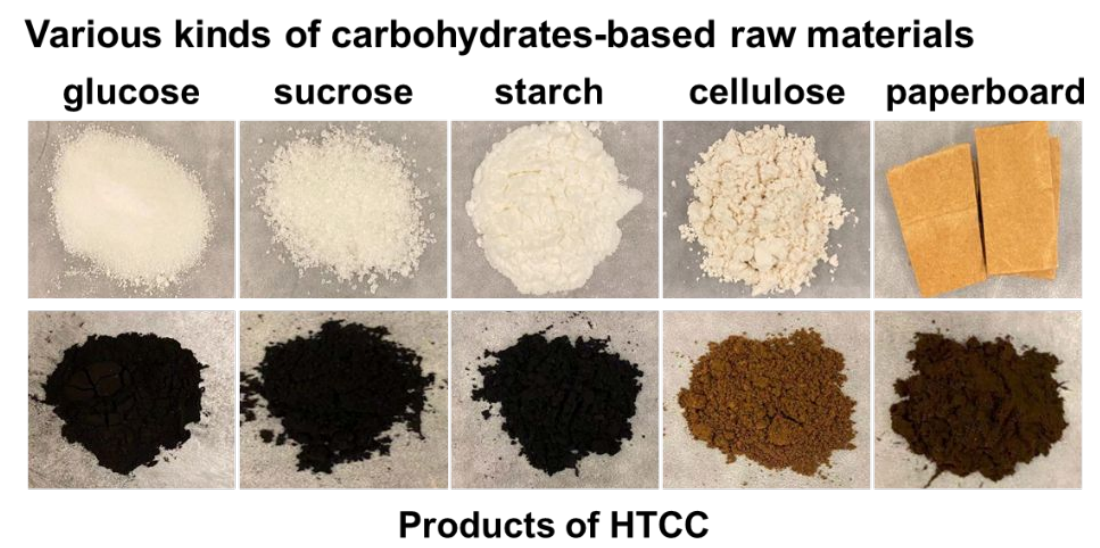

Figure S2. Various kinds of biomass raw materials and their corresponding HTCC products.
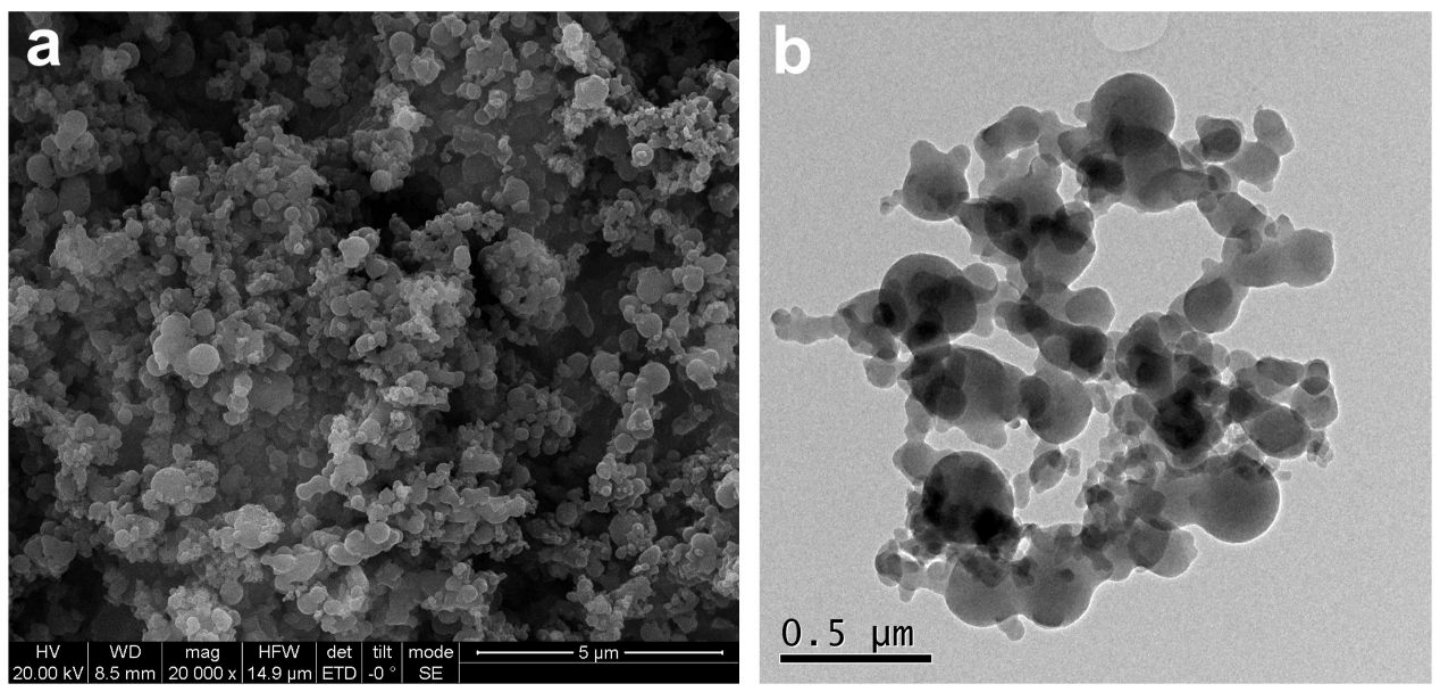

Figure S3. SEM (a) and TEM (b) images of HTCC 

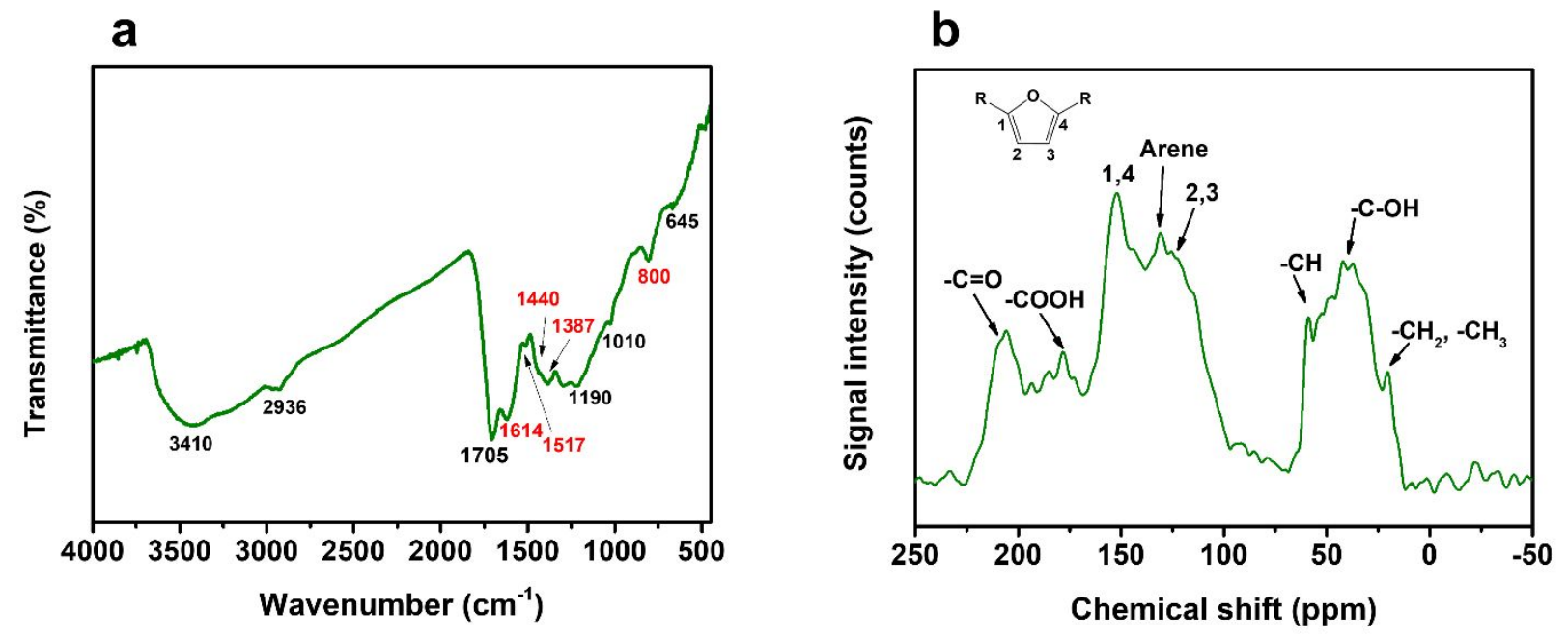

Figure S4. (a) FT-IR spectrum, and (b) ${ }^{13} \mathrm{C}$ Solid-state CP-MAS NMR spectrum of HTCC.

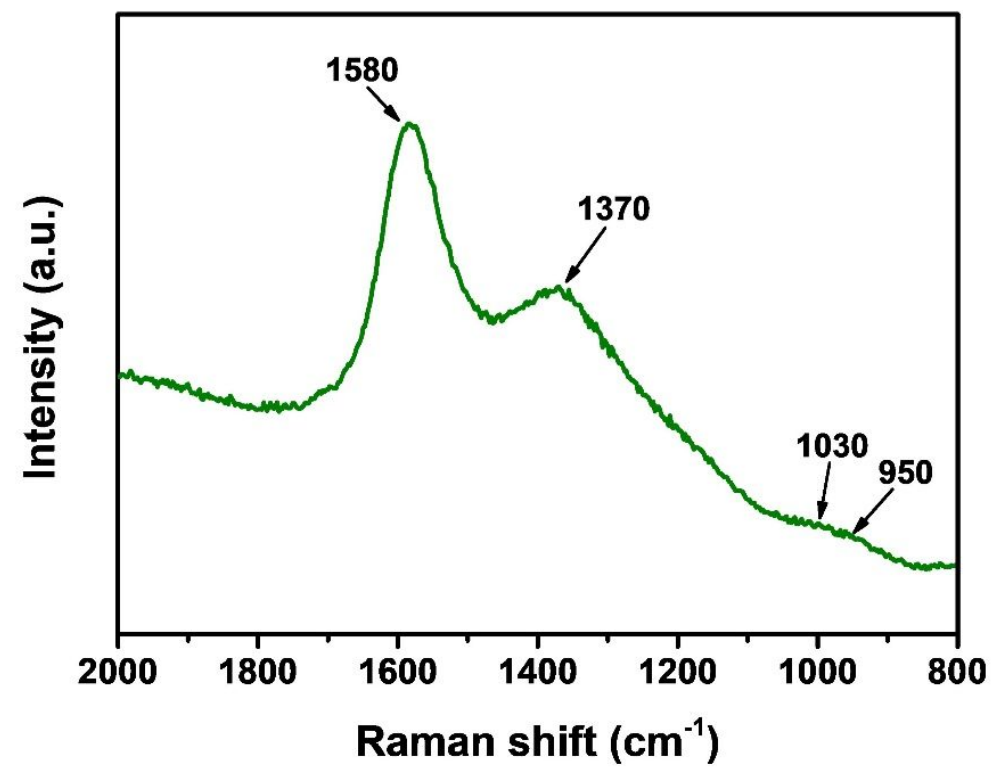

Figure S5. Raman spectrum of HTCC. 

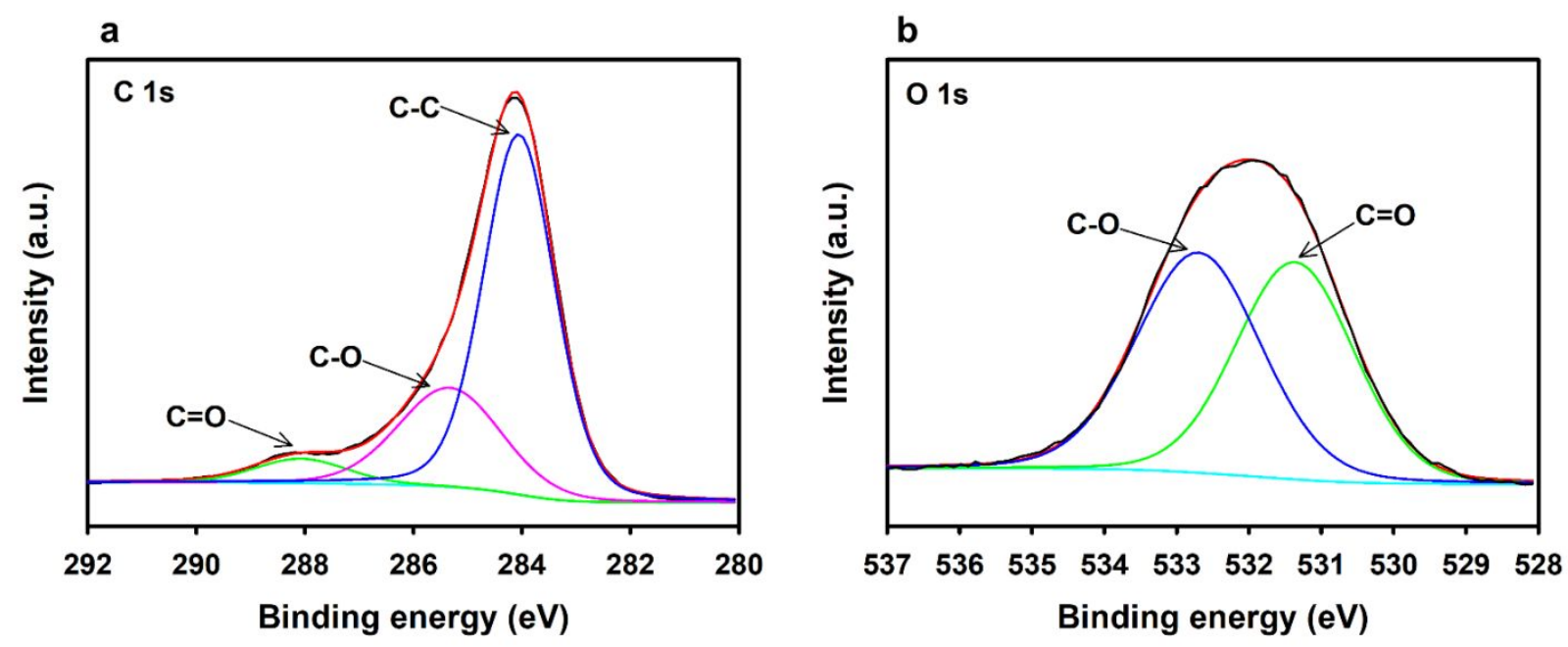

Figure S6. High resolution C 1s and O 1s spectra of HTCC.

Text S1. Calculation of apparent quantum efficiency ( $\left.\Phi_{A Q Y}\right)$ for $\mathrm{H}_{2} \mathrm{O}_{2}$.

The apparent quantum yield $\left(\Phi_{\mathrm{AQY}}\right)$ is calculated via the following equation:

$$
\Phi^{\mathrm{AQY}}=\frac{\left[\text { the number of evolved } \mathrm{H}_{2} \mathrm{O}_{2} \text { molecules } \times 2\right]}{\text { amount of photons absorbed }}
$$

The amount of photons absorbed $(\mathrm{N})$ was calculated by the following equation.

$$
\mathrm{N}=\frac{\mathrm{E} \lambda}{\mathrm{hc}}=\frac{\mathrm{P} \times \mathrm{a} \times \mathrm{t} \times \lambda}{\mathrm{hc}}
$$

Where $\mathrm{P}$ is intensity of light source at $420 \mathrm{~nm}\left(2.6 \mathrm{~mW} \mathrm{~cm}^{-2}\right)$, a is the irradiated region $(5.1$ $\left.\mathrm{cm}^{2}\right), \mathrm{t}$ is the irradiation time ( 1 hour), $\lambda$ is the wavelength of light $(420 \mathrm{~nm}), \mathrm{h}$ is Planck constant $\left(6.63 \times 10^{-34} \mathrm{~J} \cdot \mathrm{s}\right)$, and $\mathrm{c}$ is the speed of light $3.00 \times 10^{8} \mathrm{~m} / \mathrm{s}$.

The production of $\mathrm{H}_{2} \mathrm{O}_{2}$ under irradiation of $420 \mathrm{~nm}$ light in 1 hour is $15.36 \mu \mathrm{mol}$. Therefore, the number of produced $\mathrm{H}_{2} \mathrm{O}_{2}$ molecules is $15.36 \times \mathrm{N}_{\mathrm{A}}=9.25 \times 10^{18}$. The $\mathrm{N}_{\mathrm{A}}$ is the Avogadro constant $\left(6.02 \times 10^{23} \mathrm{~mol}^{-1}\right)$. Finally, the $\Phi_{\mathrm{AQY}}$ of $\mathrm{HTCC}$ is calculated to be $18.2 \%$. 
Table S1. Comparing the photocatalytic performance of HTCC and $g-\mathrm{C}_{3} \mathrm{~N}_{4}$ on $\mathrm{H}_{2} \mathrm{O}_{2}$ synthesis.

\begin{tabular}{|c|c|c|c|}
\hline Material & $\begin{array}{c}\mathrm{H}_{2} \mathrm{O}_{2} \text { synthesis rate } \\
\text { over mass of catalyst } \\
\quad\left(\mathrm{mmol} \mathrm{gcat}^{-1} \mathrm{~h}^{-1}\right)\end{array}$ & $\begin{array}{c}\mathrm{H}_{2} \mathrm{O}_{2} \text { synthesis rate } \\
\text { over surface area of } \\
\text { catalyst }\left(\mathrm{mmol} \mathrm{cm}^{-2} \mathrm{~h}^{-1}\right)\end{array}$ & $\begin{array}{l}\text { Turnover frequency } \\
\left(\text { TOF }, \mathbf{h}^{-1}\right)\end{array}$ \\
\hline HTCC & 1.16 & 77.19 & $7.9 \times 10^{-5}$ \\
\hline $\mathrm{g}-\mathrm{C}_{3} \mathrm{~N}_{4}$ & 0.02 & 0.73 & $2.2 \times 10^{-6}$ \\
\hline
\end{tabular}

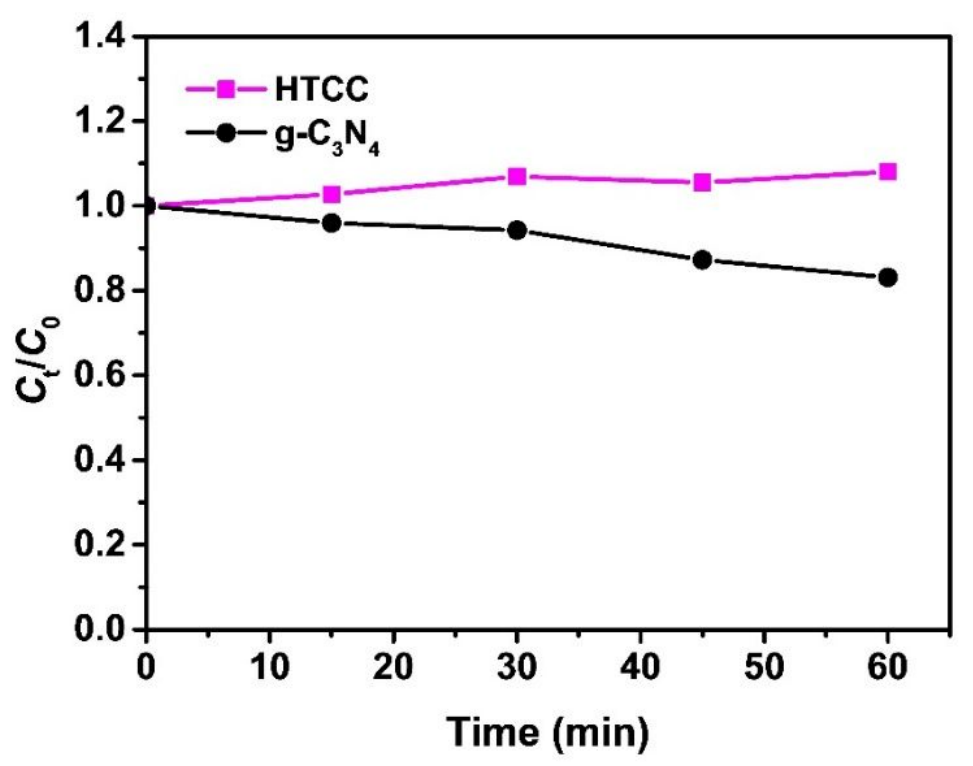

Figure S7. Decomposition of $\mathrm{H}_{2} \mathrm{O}_{2}$ (initially at $0.5 \mathrm{mmol} \mathrm{L}^{-1}$ ) in photocatalytic system of HTCC and $\mathrm{g}-\mathrm{C}_{3} \mathrm{~N}_{4}$ under $\mathrm{N}_{2}$ atmosphere.

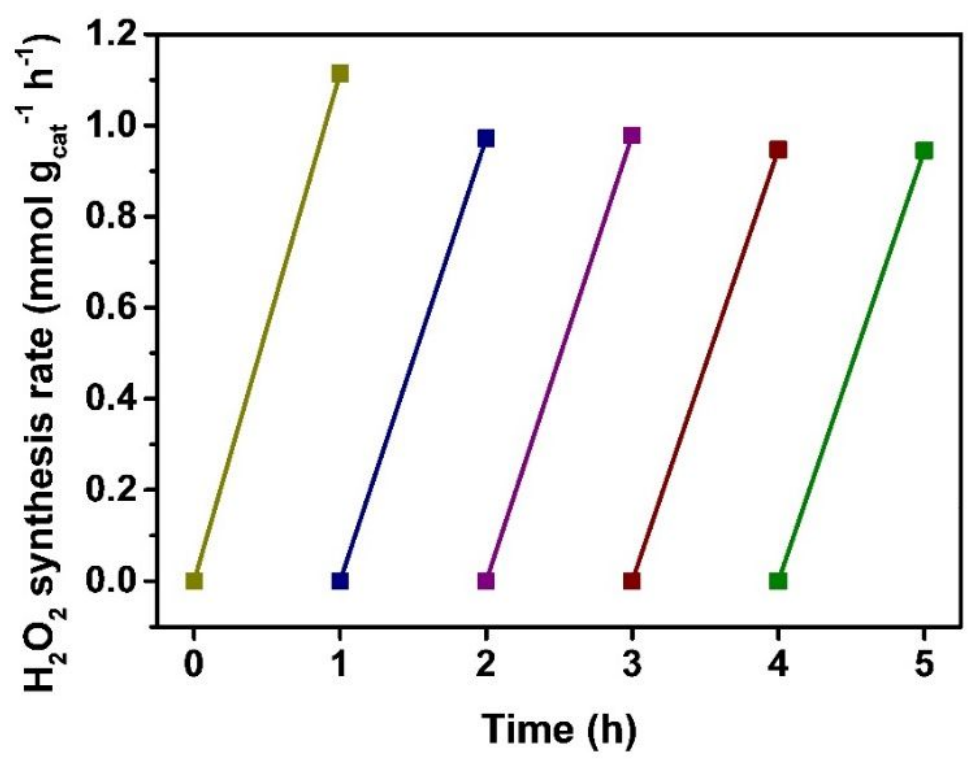

Figure S8. Cycling test on $\mathrm{H}_{2} \mathrm{O}_{2}$ synthesis using $\mathrm{HTCC}$ photocatalyst under visible-light 
irradiation.
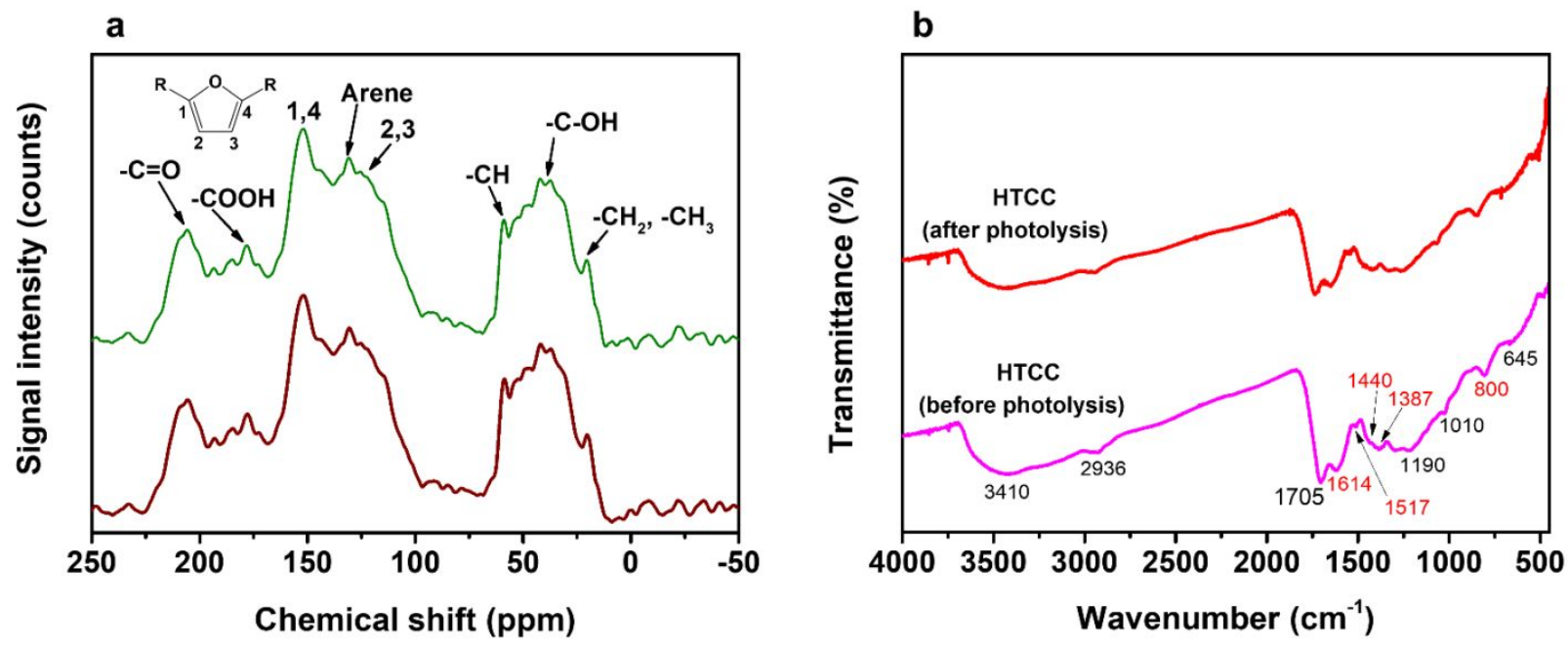

Figure S9. (a) ${ }^{13} \mathrm{C}$ Solid-state CP-MAS NMR spectra, and (b) FT-IR spectra of HTCC before and after photocatalysis.

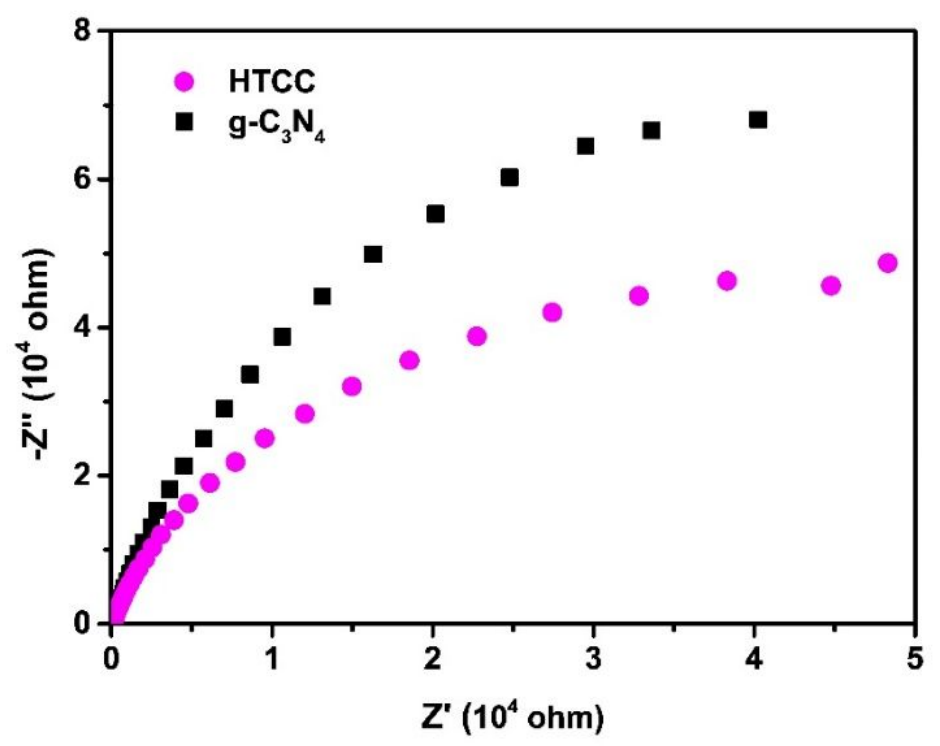

Figure S10. Nyquist plots of $\mathrm{HTCC}$ and $\mathrm{g}-\mathrm{C}_{3} \mathrm{~N}_{4}$. 


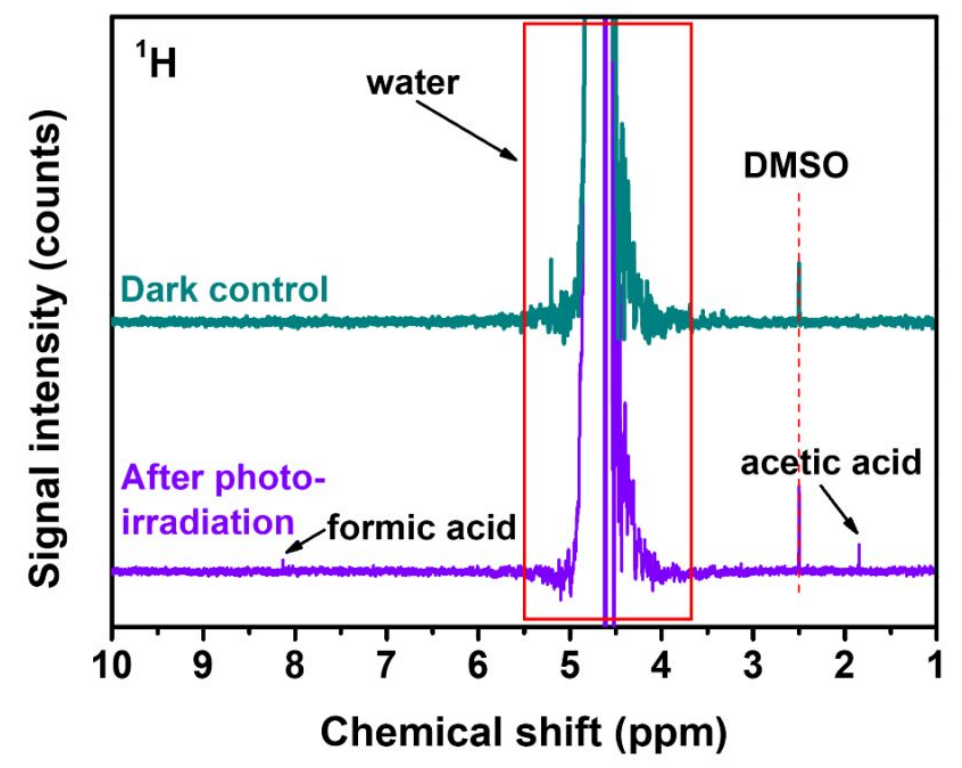

Figure S11. Analysis of the reaction solution of $\mathrm{HTCC}$ with/without photo-irradiation by ${ }^{1} \mathrm{H}$ NMR. DMSO is the solvent standard.

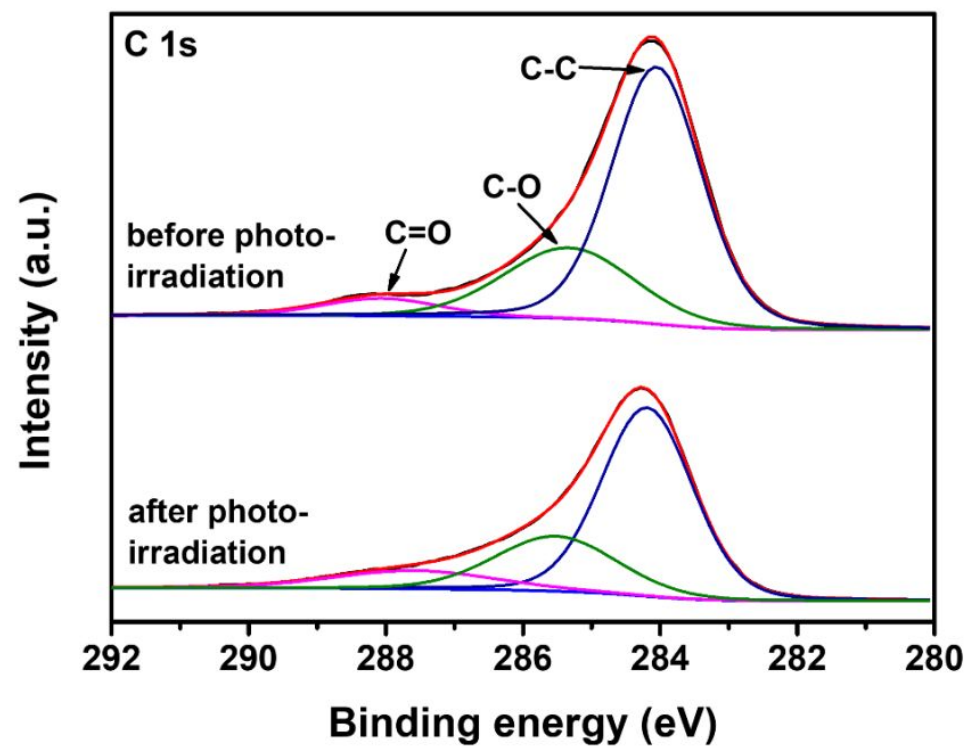

Figure S12. High-resolution C 1s XPS spectra of HTCC before and after photo-irradiation. The ratio of $\mathrm{C}=\mathrm{O}$ increases, while the ratio of $\mathrm{C}-\mathrm{O}$ and $\mathrm{C}-\mathrm{C}$ decrease (Table S2). Hence, there is a transformation of $\mathrm{C}-\mathrm{O}$ and $\mathrm{C}-\mathrm{C}$ to $\mathrm{C}=\mathrm{O}$ when $\mathrm{HTCC}$ is exposed to photo-irradiation. 
Table S2. Atomic ratio of different states C in HTCC.

\begin{tabular}{cccc}
\hline Materials & $\mathbf{C}=\mathbf{O}$ & $\mathbf{C - O}$ & $\mathbf{C - C}$ \\
\hline HTCC before photoreaction & 0.06 & 0.26 & 0.68 \\
\hline HTCC after photoreaction & 0.11 & 0.23 & 0.66 \\
\hline
\end{tabular}

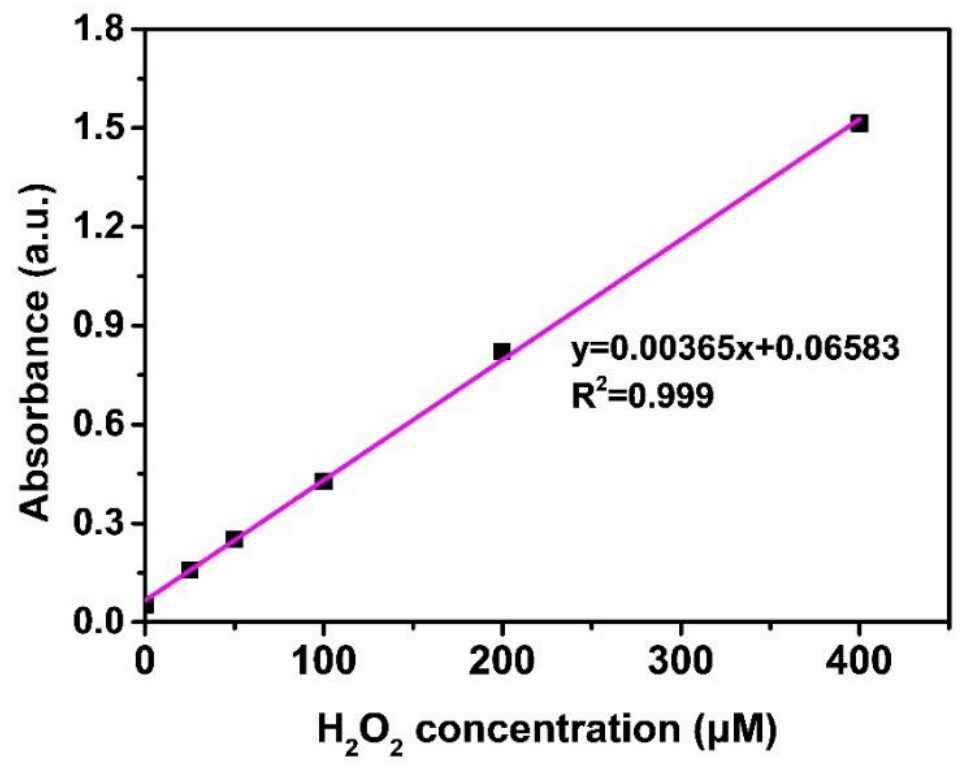

Figure S13. Calibration curve for quantification of $\mathrm{H}_{2} \mathrm{O}_{2}$. 